\title{
NHS leaders remind frontline staff to be alert to Ebola infection
}

\section{Zosia Kmietowicz}

The BMJ

Frontline health staff in England have been reminded to consider the risk of Ebola virus infection in anyone who has recently travelled from west Africa and anyone who has a fever.

The United Kingdom is at the highest risk outside Africa of seeing cases of Ebola, said Bruce Keogh, the medical director of the NHS in England, Bob Winter, the national clinical director for emergency preparedness, and colleagues.

In a letter and a rapid response to The $B M J$ they said that people who are suspected of infection should be immediately isolated and, if they are being seen in the community, transferred to hospital by ambulance, with advance warning being given to the accepting hospital so that adequate precautions can be followed. $^{12}$

The rapid response says, "While there have been no cases of Ebola diagnosed to date in the UK, and the risk of spread remains relatively low, the patterns of extensive global travel mean that the risk of importation of Ebola to the UK is considered to be the highest outside of Africa. It is therefore important for frontline staff to be mindful and vigilant of Ebola when patients present to NHS services."

It tells frontline NHS staff to be vigilant with regard to Ebola virus infection in anyone who has been to west Africa in the past 21 days and anyone with a fever. "Other symptoms they may be complaining of include headache, joint and muscle pain, a sore throat, and muscle weakness," it adds.

All suspected cases of Ebola virus infection should be reported to the senior clinicians on duty, the consultant who is on call for infection, and the local Public Health England health protection team.
Only a clinician who is trained in using the appropriate standard of personal protective equipment should take the full clinical history, including travel history and potential exposure, say Keogh and colleagues. Protective measures for handling patients infected with Ebola virus include hand hygiene, gloves, a water repellent gown and overshoes, a fluid repellent surgical facemask, and eye protection.

In cases where patients were not being immediately isolated - for example, if they have been sitting in a waiting room- "then they should be isolated as soon as the risk has been identified, the area where they have been is to be cordoned off, and the names of any staff or patients who may have come in contact with them is to be documented," says the rapid response. It adds, "If the patient is deemed at risk of having Ebola, then that area must not be used again until it has been decontaminated as per the ACDP [Advisory Committee on Dangerous Pathogens] guidelines." 3

Access all of The BMJs content on the ongoing Ebola outbreak at thebmj.com/ebola.

1 Finn RP, Smith C, Ghafur S, Zarkali A, Adlington K, Winter B, et al. Time to think Ebola: a message from NHS England to frontline clinical staff. BMJ 2014:349:96776.

2 Finn RP, Smith C, Ghafur S, Zarkali A, Adlington K, WinterB, et al. Time to think Ebola: a message from the national medical director to frontline clinical staff [electronic response to O'Dowd A. NHS staff readied to deal with Ebola cases in hospitals and general practices]. BMJ 11 Nov 2014. www.bmj.com/content/349/bmj.g6449/rr/779739.

3 Advisory Committee on Dangerous Pathogens. Management of hazard group 4 viral haemorrhagic fevers and similar human infectious diseases of high consequence: guidance. 2014. https://www.gov.uk/government/uploads/system/uploads/attachment_ data/file/354641/VHF_algorithm_10_09_2014.pdf. 